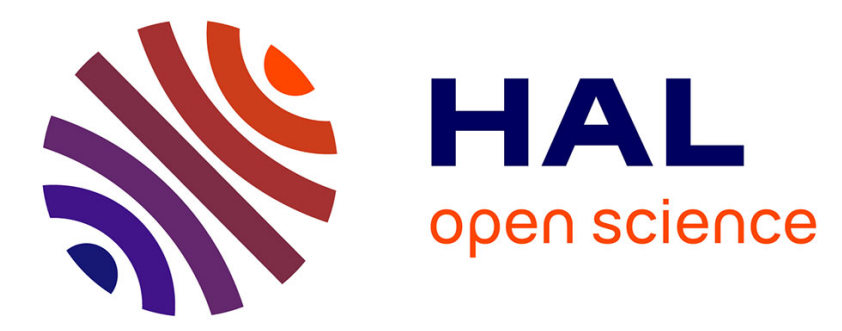

\title{
The Mg-rich phase NdNiMg15: structural and magnetic properties
}

\author{
Eliane Al Asmar, Sophie Tencé, Jean-Louis Bobet, Bassem Ourane, Michel \\ Nakhl, Mirvat Zakhour, Etienne Gaudin
}

\section{> To cite this version:}

Eliane Al Asmar, Sophie Tencé, Jean-Louis Bobet, Bassem Ourane, Michel Nakhl, et al.. The Mg-rich phase NdNiMg15: structural and magnetic properties. Inorganic Chemistry, 2018, 57 (22), pp.1415214158. 10.1021/acs.inorgchem.8b02007 . hal-01942628

\section{HAL Id: hal-01942628 \\ https://hal.science/hal-01942628}

Submitted on 4 Mar 2021

HAL is a multi-disciplinary open access archive for the deposit and dissemination of scientific research documents, whether they are published or not. The documents may come from teaching and research institutions in France or abroad, or from public or private research centers.
L'archive ouverte pluridisciplinaire HAL, est destinée au dépôt et à la diffusion de documents scientifiques de niveau recherche, publiés ou non, émanant des établissements d'enseignement et de recherche français ou étrangers, des laboratoires publics ou privés. 


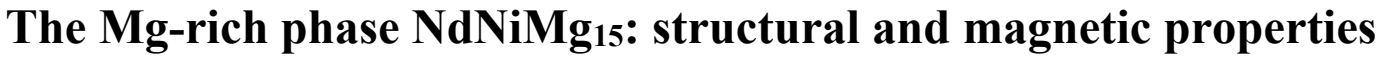

\author{
Eliane Al Asmar ${ }^{1,2,3}$, Sophie Tencé ${ }^{1,2}$, Jean-Louis Bobet ${ }^{1,2}$, Bassem Ourane ${ }^{1,2}$, Michel Nakhl ${ }^{3}$, \\ Mirvat Zakhour ${ }^{3}$, and Etienne Gaudin ${ }^{1,2, *}$ \\ ${ }^{1}$ CNRS, ICMCB, UMR 5026, F-33600 Pessac, France \\ ${ }^{2}$ Univ. Bordeaux, ICMCB, UMR 5026, F-33600 Pessac, France \\ ${ }^{3}$ LCPM/PR2N (EDST), Université Libanaise, Faculté des Sciences II, 90656, Jdeidet El Metn, \\ Lebanon \\ *etienne.gaudin@icmcb.cnrs.fr
}

\begin{abstract}
The intermetallic $\mathrm{NdNiMg}_{15}$ is the Mg-richest phase (more than 88 at $\%$ of $\mathrm{Mg}$ ) discovered in the $\mathrm{Mg}-\mathrm{Nd}-\mathrm{Ni}$ system. Its structure was determined by X-ray diffraction on single-crystal with the following crystal data: tetragonal system, $\mathrm{P} 4 / \mathrm{nmm}, \mathrm{Z}=2, a=10.0602(1) \AA, c=7.7612(2) \AA$, $\mathrm{d}_{\mathrm{calc}}$ $=2.40 \mathrm{~g} . \mathrm{cm}^{-3}$. Its structure is made of a 3-Dimensional framework of magnesium atoms showing channels filled by $1 \mathrm{D}$ chain consisting of alternating $\mathrm{Nd}$ and $\mathrm{Ni}$ atoms along the $c$-axis. Antiferromagnetic ordering was observed with $\mathrm{T}_{\mathrm{N}}=9 \mathrm{~K}$, which is remarkably high considering the long distances between magnetic atoms, i.e $\mathrm{Nd}$ atoms. The effective magnetic moment $\mu_{\mathrm{eff}}$ is equal to $3.58 \mu_{\mathrm{B}}$ which is consistent with magnetic $\mathrm{Nd}^{3+}$ ions and weakly or non-magnetic $\mathrm{Ni}$-atoms. Below $\mathrm{T}_{\mathrm{N}}$, the $\mathrm{M}(\mathrm{H})$ curves show field induced metamagnetic transitions at critical fields increasing with decreasing temperatures. The magnetic structure of $\mathrm{NdNiMg}_{15}$ was determined from neutron powder diffraction data by considering the propagation vector $\mathbf{k}=(1 / 21 / 20)$. This magnetic structure consists in ferromagnetic chains along the $c$-axis of $\mathrm{Nd}$ atoms carrying moments, only separated by $\mathrm{Ni}$ atoms. The chains are ferromagnetically coupled within planes perpendicular to the [110] direction and these planes are antiferromagnetically coupled to neighboring planes forming a checkerboard-like magnetic structure.
\end{abstract}




\section{Introduction}

The interest in magnesium alloys has increased over the past thirty years, especially because magnesium is abundant in nature, cheap and lightweight and has very diverse applications (automobile, aerospace, hydrogen storage...). Numerous studies have been devoted to the search of new Mg-based light structural materials, mainly for automobile and aeronautic industry components ${ }^{1,2}$ and for biomedical applications ${ }^{3,4}$. Besides these structural applications, magnesium and magnesium alloys are also good candidates for solid storage of hydrogen through the formation of metal hydrides $^{5,6}$. Magnesium exhibits very high hydrogen storage capacity (i.e. 7.6 wt.\%, $110 \mathrm{gH} / \mathrm{L}$ by formation of $\mathrm{MgH}_{2}$ ), but its use remains limited due to the high operating temperature (around $300^{\circ} \mathrm{C}$ ) and the heat released by the highly exothermic absorption reaction ${ }^{5}$. In addition, a new interest in the hydrolysis reaction between $\mathrm{Mg}$ or $\mathrm{Mg}$ alloys and water for hydrogen generation has recently emerged. This would be an interesting way to valorize $\mathrm{Mg}$-based alloys wastes ${ }^{7,8}$. For all these reasons, a reinvestigation of the Mg-rich zone of many ternary (and quaternary) systems has been carried out in the last years.

In the case of structural materials, extensive studies of the RE- $\mathrm{Zn}-\mathrm{Mg}$ systems close to the $\mathrm{Mg}$ corner have led to the discovery of a new series of so-called Long Period Stacking Ordered (LPSO) phases $^{9}$. The strength and ductility of $\mathrm{Mg}-\mathrm{Y}-\mathrm{Zn}$ alloys are strongly enhanced when they are produced by rapid solidification processing ${ }^{10}$. After this process, intermetallic particles, so-called LPSO, precipitate and are distributed along the Mg grains boundaries. The LPSO phases are long period stacking variants of the structure of hcp-Mg and the most frequently polytypes observed crystallize with a $18 \mathrm{R}, 14 \mathrm{H}$ or $10 \mathrm{H}$ structure ${ }^{11,12}$. The RE and $\mathrm{Zn}$ atoms are located in some of the layers and they form $\mathrm{Zn}_{6} \mathrm{RE} 8$ clusters. The Mg-rich corner of many RE-TM-Mg ternary systems ( $\mathrm{RE}=$ Rare-Earth, $\mathrm{TM}=$ Transition Metal) have been also studied for solid hydrogen storage, in order to combine the low weight of magnesium and the catalytic effect of rare-earth and transition metal ${ }^{13,14,15}$. Among these systems one can cite the La-Ni-Mg ${ }^{15,16}$ and $\mathrm{Nd}-\mathrm{Ni}-\mathrm{Mg}^{17-21}$ systems. The different studies show a decomposition of the intermetallic compounds into $\mathrm{MgH}_{2}$, binary rareearth hydrides (e.g. $\mathrm{LaH}_{3}$ ) and ternary magnesium transition metal hydrides (e.g. $\left.\mathrm{Mg}_{2} \mathrm{NiH}_{4}\right)$. An increase of the kinetics of the hydrogen sorption properties of $\mathrm{Mg}$ is observed but no real breakthrough concerning the solid storage of hydrogen was achieved. The stabilization of these ternary phases upon hydrogenation is still an interesting challenge to overcome to find new candidates for solid hydrogen storage.

The reinvestigation of many ternary RE-TM-Mg systems has led to the discovery of numerous new very-rich $\mathrm{Mg}$ phases and has extended our knowledge of these ternary systems. Some of these ternary phases are disordered ${ }^{22,11}$ or derive from binary phases ${ }^{23,24}$. For instance, $\mathrm{Gd}_{13} \mathrm{Ni}_{9} \mathrm{Mg}_{78}{ }^{22}$ crystallizes with a modulated structure which derives from an average cubic structure and 
$\mathrm{LaCuMg}_{8}{ }^{23}$ crystallizes in the $\mathrm{La}_{2} \mathrm{Mg}_{17}$-type structure with $\mathrm{Cu}$ atoms located in interstitial sites or partially substituted to $\mathrm{Mg}$ atoms on one atomic position. Among the ordered ones one can cite $\mathrm{NdNiMg}_{5}{ }^{18}, \mathrm{Mg}_{30} \mathrm{Co}_{2} \mathrm{Y}_{9}{ }^{25}, \mathrm{Ce}_{2} \mathrm{Ru}_{4} \mathrm{Mg}_{17}{ }^{26}, \mathrm{Nd}_{16} \mathrm{Mg}_{96} \mathrm{Ni}_{12}{ }^{21}, \mathrm{Nd}_{4} \mathrm{Ni}_{8} \mathrm{Mg}_{80}{ }^{20}$ and the title compound $\mathrm{NdNiMg}_{15}{ }^{27}$ with increased molar ratio of magnesium (from $71.4 \%$ to $88.2 \%$ ). Except of $\mathrm{NdNiMg}_{5}$ which crystallizes with an ordered variant of the $\mathrm{Nd}_{3} \mathrm{Co}_{3} \mathrm{Ga}$-type structure, all these compounds crystallize with new structural types. Only the magnetic properties of $\mathrm{Ce}_{2} \mathrm{Ru}_{4} \mathrm{Mg}_{17}$ and $\mathrm{NdNiMg}_{5}$ have been studied. No magnetic ordering was observed down to $3 \mathrm{~K}$ for the former compound and this has been correlated to an almost tetravalent state of Ce atoms. An antiferromagnetic ordering is observed below $\mathrm{T}_{\mathrm{N}}=12 \mathrm{~K}$ for $\mathrm{NdNiMg}_{5}$, and the value of the effective magnetic moment confirms that the prevalent contribution to magnetism comes from the $\mathrm{Nd}$ atoms. Among the LPSO phases discovered, recently Kishida et al. have determined the crystal structure of three phases with composition $\mathrm{Y}_{4} \mathrm{Zn}_{3} \mathrm{Mg}_{23}, \mathrm{Y}_{4} \mathrm{Zn}_{3} \mathrm{Mg}_{29}$ and $\mathrm{Y}_{4} \mathrm{Zn}_{3} \mathrm{Mg}_{35}{ }^{12}$. Up to now, $\mathrm{NdNiMg}_{15}$ is the richest $\mathrm{Mg}$ ordered ternary crystalline phase ever discovered. In a recent paper we have presented the interest of this compound for hydrogen generation ${ }^{27}$. The crystal structure and the magnetic properties and structure of this peculiar compound are reported herein.

\section{Experimental section}

The starting materials for the preparation of the sample were neodymium pieces (ZLX Tech, $>99.9 \%$ ), a nickel rod (Strem Chemicals, >99.9\%), and a magnesium rod (Alpha Aesar, >99.8\%). To avoid oxides impurities, the surfaces of the magnesium and neodymium pieces were carefully cleaned with abrasive tools. The $\mathrm{Nd}, \mathrm{Ni}$ and $\mathrm{Mg}$ elements were then weighed in the 1:1:15 atomic ratio and sealed in small tantalum ampoules under an argon pressure of ca. 800 mbar. The argon was purified before with magnesium sponge $(673 \mathrm{~K})$. Then, the ampoules were placed in a high frequency furnace under argon and heated at about $1773 \mathrm{~K}$ and kept at that temperature for 2 min. The tantalum ampoule was then enclosed in an evacuated quartz tube and annealed at $973 \mathrm{~K}$ for 10 days. The temperature was decreased to room temperature at $6 \mathrm{~K} / \mathrm{h}$.

A crystal suitable for single-crystal X-ray diffraction was selected on the basis of the size and sharpness of the diffraction spots. Data collection was carried out using a Bruker Kappa Apex II diffractometer (Mo-radiation) at room temperature. Numerical absorption correction using the shape of the crystal (face indexed with the help of the video microscope) was made with SADABS$2014 / 5^{28}$ software. The unit cell is tetragonal with lattice parameters $\mathrm{a}=10.0602(1)$ and $\mathrm{c}=$ 7.7612(2) A. The space group and structural determinations were performed with the Jana2006 program package ${ }^{29}$. The extinction conditions observed agree with the $P 4 / \mathrm{nmm}$ space group (the origin choice 2 has been chosen for comparison with the isotype structures). All the atomic positions were located using the SUPERFLIP program ${ }^{30}$. Refinement of the occupancy parameters 
showed full occupancy within two standard deviations. At the end of the refinement, with anisotropic atomic displacement parameters for all atomic positions, the reliability factors were R[F2 > $2 \sigma(\mathrm{F} 2)]=0.012$ and $w \mathrm{R}(\mathrm{F} 2)=0.030 . \mathrm{R} / \mathrm{Rw}, \mathrm{S}=1.00$ for 31 parameters, 805 independent reflections and with residual electron density in the range $\left[-0.33,+0.51\right.$ e. $\left.\AA^{-3}\right]$. Details of data collections and structure refinement can be found in the crystallographic information file (CIF) deposited in the Fachinformationszentrum Karlsruhe (FIZ, 76344 Eggenstein-Leopoldshafen Germany); with reference CSD 434727. The atomic positions are given in table 1.

Magnetization measurements were performed using a SQUID magnetometer from Quantum Design for temperatures from 1.8 to $360 \mathrm{~K}$ and magnetic fields up to $7 \mathrm{~T}$.

Neutron diffraction experiments were carried out at the Laue Langevin Institute (ILL) on the D1B diffractometer with the use of a wavelength of $2.524 \AA$. A cylindrical vanadium sample holder of $6 \mathrm{~mm}$ inner diameter was used to collect neutron data. The FullProf Suite program was used for nuclear and magnetic structure refinements using the Rietveld method ${ }^{31}$.

\section{Results and Discussion}

\section{Crystal structure}

The structure of $\mathrm{NdNiMg}_{15}$ is made of a three-dimensional network of magnesium atoms giving rise to channels along the $c$ axis where chains made of nickel and neodymium atoms are located (figure 1). The channels consist in infinite face-sharing chains of $\left[\mathrm{Mg}_{8}\right]$ square antiprism filled alternatively by $\mathrm{Ni}$ and $\mathrm{Nd}$ atoms and a connection between the chains of $\mathrm{Mg} 8$ square prisms through Mg6-Mg6 bonds can be considered (figure 2a). The Ni-Nd distances observed in the chain, equal to 3.858 and $3.903 \AA$ (table 2 ), are very long compared to the sum of the metallic radii, 3.07 $\AA\left(\mathrm{r}_{\mathrm{Nd}}=1.82\right.$ and $\mathrm{r}_{\mathrm{Ni}}=1.25 \AA^{32}$ and of the covalent radii, $2.79 \AA\left(\mathrm{r}_{\mathrm{Nd}}=1.64\right.$ and $\left.\mathrm{r}_{\mathrm{Ni}}=1.15 \AA^{33}\right)$. Then, the bonding between Nd1 and Nil is expected to be rather weak. The Ni-Mg distances in the $\left[\mathrm{Mg}_{8}\right]$ square antiprism, equal to 2.641 and $2.669 \AA$, are very close to the sum of the covalent radius of $\mathrm{Ni}$ and atomic of $\mathrm{Mg}, 2.75 \AA\left(\mathrm{r}_{\mathrm{Mg}}=1.60 \AA^{33}\right)$. For the discussion of distances with $\mathrm{Mg}$ atoms, the covalent radius $\left(\mathrm{r}_{\mathrm{Mg}}=1.36 \AA^{33}\right)$ has not been taken into account because of its too low value which is not realistic in the case of intermetallic chemistry. Then the atomic radius of 1.60 $\AA$ has been considered and moreover it corresponds also to the metallic radius ${ }^{34}$. By considering the two shortest Nd-Mg distances of 3.394 and $3.474 \AA$ (table 2), the $\mathrm{Nd}$ atom has eight $\mathrm{Mg}$ neighbors which form a square antiprism. These distances are very close to the sum of the metallic radii $(1.82+1.60=3.42 \AA)$. By slightly increasing the Nd-Mg distances up to $3.6 \AA$ the coordination polyhedra becomes more complex (figure $2 \mathrm{~b}$ ) with $16 \mathrm{Mg}$-neighbors, 24 triangular faces and 
2 square faces. In $\mathrm{NdNiMg}_{5}{ }^{18}$ different coordination polyhedra around $\mathrm{Ni}$ and $\mathrm{Nd}$ atoms are observed but the Ni-Mg and $\mathrm{Nd}-\mathrm{Mg}$ distances are very close to the ones observed for $\mathrm{NdNiMg}_{15}$. They range from 2.668 to $2.804 \AA$ for Ni-Mg and from 3.292 to $3.416 \AA$ for Nd-Mg (only the distances below $3.60 \AA$ are considered). To describe the 3D-network of magnesium atoms one can consider three roughly regular $\mathrm{Mg}_{4}$ tetrahedra sharing faces or edges (figure $3 \mathrm{a}$ and $3 \mathrm{~b}$ ). The most regular tetrahedron is $[\mathrm{Mg} 4]_{4}$ with $\mathrm{Mg} 4-\mathrm{Mg} 4$ distances equal to 3.055 and $3.182 \AA$ and the angles between the center of the tetrahedra and the vertices equal to 105.2 and $111.7^{\circ}$. The two other types of tetrahedra are more distorted with in each case a long edge with a length equal to 3.265 $\AA$ for $\mathrm{Mg} 3-\mathrm{Mg} 7$ and $3.451 \AA$ for $\mathrm{Mg} 4-\mathrm{Mg} 7$. A view of the structure with a drawing of these tetrahedra is shown in figure $3 \mathrm{c}$. The average distance between the center of these three tetrahedra and their vertices is equal to $1.94 \AA$ which is exactly the same value as the one observed in Mg-metal ${ }^{27}$. Moreover the Mg-Mg distances are ranging from 2.944 to 3.451 (table 2) and are consistent with the value of $3.2 \AA$ observed in Mg-metal. All these structural features suggest the metallic character of the Mg-network. The structure of $\mathrm{NdNiMg}_{15}$ can be considered as an ordered variant of the $\mathrm{V}_{15} \mathrm{Sb}_{18}{ }^{35}$ structure type. Only few compounds crystallize with this structural type, one can cite $\mathrm{Ti}_{8} \mathrm{Bi}_{9}{ }^{36}, \mathrm{Zr}_{2} \mathrm{~V}_{6} \mathrm{Sb}_{9}{ }^{37}, \mathrm{Ti}_{5.42} \mathrm{Mo}_{2.58} \mathrm{Sb}_{9}{ }^{38}$ or $\mathrm{Ce}_{2} \mathrm{Pd}_{14} \mathrm{Si}^{39}$. It may be noticed that the ICSD database ${ }^{40}$ has chosen the $\mathrm{Zr}_{2} \mathrm{~V}_{6} \mathrm{Sb}$ 9 structure as structure-type even if the $\mathrm{V}_{15} \mathrm{Sb}_{18}$ structure (or Bi8Ti9) has been published earlier. To our knowledge $\mathrm{NdNiMg}_{15}$ is the first $\mathrm{Mg}$-based phase crystallizing with this structural-type.

The structures of the four very Mg-rich phases recently discovered in the Nd-Ni-Mg system can be described as made of a three-dimensional metallic framework of magnesium atoms and of a covalent network of $\mathrm{Nd}-\mathrm{Ni}$ atoms with lower dimensionality. A 2D-network is observed in $\mathrm{NdNiMg} 5_{5}{ }^{18}$, the $\mathrm{Nd}$ and $\mathrm{Ni}$ atoms forming ordered graphitic-type layer perpendicular to the $c$-axis and a 1D-network in $\mathrm{NdNiMg}_{15}$ with chains alternatively made of $\mathrm{Nd}$ - and $\mathrm{Ni}$-atoms running along the $c$ axis. In the case of $\mathrm{Nd}_{4} \mathrm{Ni}_{8} \mathrm{Mg}_{80}{ }^{20}$ only $\mathrm{Nd}$ and $\mathrm{Ni}$ isolated atoms are observed whereas in $\mathrm{Nd}_{16} \mathrm{Ni}_{12} \mathrm{Mg}_{96}{ }^{21} \mathrm{Nd}_{4} \mathrm{Ni} 2$ clusters and isolated $\mathrm{Ni}$-atoms are coexisting. As briefly discussed in the introduction, the coexistence of a metallic Mg-matrix and clusters of rare-earth and transition metal was previously observed in Mg-rich LPSO phases (see Y-Zn-Mg ${ }^{12}$ system for instance) and led to drastic changes in mechanical properties ${ }^{10}$.

\section{Magnetic properties}

The plot of the magnetization divided by the applied magnetic field, $\mathrm{M} / \mathrm{H}$, of $\mathrm{NdNiMg}_{15}$ is reported on figure 4 . On this curve, we clearly distinguish a peak at $9 \mathrm{~K}$ indicating the establishment of an antiferromagnetic ordering. As shown in the inset of figure 4, the inverse of the magnetic susceptibility measured at $3 \mathrm{~T}$ exhibits a small curvature in the paramagnetic domain. Thus, 
the data above $T_{N}$, were fitted with a modified Curie-Weiss law: $\chi=\chi_{0}+C /\left(T-\theta_{p}\right)$, where $\chi_{0}$ is a temperature-independent term, $\mathrm{C}$ the Curie constant and $\theta_{\mathrm{p}}$ the paramagnetic Curie temperature. From this fit, we obtain the following values: $\chi_{\mathrm{o}}=4.810^{-4} \mathrm{emu} / \mathrm{mol}, \mathrm{C}=1.60 \mathrm{emu} . \mathrm{K}_{\mathrm{mol}}{ }^{-1}$ and $\theta_{\mathrm{p}}$ $=-4 \mathrm{~K}$. The effective moment corresponding to the Curie constant is equal to $3.58 \mu_{\mathrm{B}}$ which is very close to the value expected for the trivalent state of the $\mathrm{Nd}^{3+}$ ion $\left(\mu\left(\mathrm{Nd}^{3+}\right)=3.62 \mu \mathrm{B}\right)$. This also indicates that $\mathrm{Ni}$ is likely not or very weakly magnetic in this compound. The slightly negative paramagnetic Curie temperature (i.e. $-4 \mathrm{~K}$ ), close to the Néel temperature, is coherent with local antiferromagnetic interactions between $\mathrm{Nd}$ atoms.

Figure 5 displays the isothermal magnetization curves at different temperatures between 1.8 and $15 \mathrm{~K}$. Above $\mathrm{T}_{\mathrm{N}}$, the $\mathrm{M}(\mathrm{H})$ curve is linear as expected for a paramagnetic state. Below the Néel temperature, the curves exhibit a linear behavior at low fields which is typical of an antiferromagnet. Besides, the curves show field induced metamagnetic transitions at critical fields increasing with decreasing temperatures. For example, the critical fields $\mathrm{H}_{\mathrm{c}}$ at 1.8 and $7 \mathrm{~K}$ are around 4.8 and $2.75 \mathrm{~T}$, respectively (see figure 5). This metamagnetic transition most likely results in a transition from an antiferromagnetic to a ferromagnetic state. The maximum value of the magnetization reaches around $2 \mu_{\mathrm{B}} / \mathrm{f}$.u. at $7 \mathrm{~T}$ but as the curve is clearly not completely satrated, one can expect a slightly higher saturated moment for $\mathrm{Nd}$ atoms.

\section{Magnetic structure}

In order to know the type of antiferromagnetic order present in $\mathrm{NdNiMg}_{15}$ we performed neutron diffraction measurements above and below $\mathrm{T}_{\mathrm{N}}$, namely between 20 and $1.8 \mathrm{~K}$ (see Figure. 6). Above the Néel temperature, the Bragg peaks, indexed with the $P 4 / \mathrm{nmm}$ space group, only correspond to the nuclear contribution. At $20 \mathrm{~K}$, the cell parameters are equal to $a=10.009(1) \AA$ and $c$ $=7.731(1) \AA$ and the refined crystal structure is in agreement with the results obtained from singlecrystal measurements at room temperature. Some small extra peaks not indexed with the $P 4 / \mathrm{nmm}$ space group, are accounted for the presence of the residual secondary phases $\mathrm{Mg}, \mathrm{Mg}_{2} \mathrm{Ni}$ and $\mathrm{NdMg}_{12}$. Below $10 \mathrm{~K}$, magnetic contributions start to grow at $2 \theta$-positions different from those of the nuclear contribution, as it can be seen on Figure 6 . These magnetic peaks are indexed with the propagation vector $\mathbf{k}=(1 / 21 / 20)$, which is coherent with the antiferromagnetic state observed at $\mathrm{T}_{\mathrm{N}}=9 \mathrm{~K}$ by magnetic measurements. This implies that the magnetic cell corresponds to the nuclear cell multiplied by two along both the $a$-axis and the $b$-axis $(2 a \times 2 b \times c)$. At $1.8 \mathrm{~K}$, the best refinement of the difference diagram $1.8 \mathrm{~K}-20 \mathrm{~K}$ is unambiguously found for an antiferromagnetic model where the magnetic moments are pointed along the $c$-axis. The refinement at $1.5 \mathrm{~K}$ and the corresponding magnetic structure are shown on figures 7 and 8 . This magnetic structure consists in ferromagnetic chains along the $c$-axis of $\mathrm{Nd}$ atoms carrying moments, only separated by $\mathrm{Ni}$ atoms. These chains are coupled to each other ferromagnetically within planes perpendicular to the [110] 
direction and antiferromagnetically between these planes leading to a checkerboard pattern in the $(a b)$ plane (figure $8 \mathrm{~b}$ ). The Nd-atoms form a puckered square lattice in the $(\mathrm{a}, \mathrm{b})$ plane with $\mathrm{Nd}-$ $\mathrm{Nd}$ distances of 7.19 and $10.06 \AA$. This latter distance corresponds to the diagonal of the square (see figure 8). The "square lattices" of Nd-atoms are stacked along the c-axis with $\mathrm{Nd}-\mathrm{Nd}$ distances of $7.76 \AA$. In the $(\mathrm{a}, \mathrm{b})$ plane, antiferromagnetic coupling is observed between Nd-atoms along the [100] or [0-10] directions (Nd-Nd distance of $10.06 \AA$ ). For the Nd-Nd distance of $7.19 \AA$, antiferromagnetic and ferromagnetic couplings that alternate are observed along the [110] directions. Ferromagnetic couplings between $\mathrm{Nd}$ atoms are observed along [-110] directions (distance of 7.19 $\AA$ ) and along the [001] direction (Nd-Nd distance of $7.76 \AA$ ). From the collinear magnetic structure, one can interpret the metamagnetic transition observed on the $\mathrm{M}(\mathrm{H})$ curve as a spin-flip transition. At the critical field value, half of the magnetic moments turn over along the direction of the field, which results in a ferromagnetic state. The magnetic moment value of $\mathrm{Nd}$ reaches $\mu_{\mathrm{Nd}}=$ $2.70(5) \mu$ в at $1.5 \mathrm{~K}$ in consistency with the magnetization measurements $\mathrm{M}(\mathrm{H})$ at low temperatures. From the various neutron patterns recorded below $\mathrm{T}_{\mathrm{N}}$, we also refined $\mu_{\mathrm{Nd}}$ in function of the temperature as depicted in figure 9. This thermal evolution confirms that the Néel temperature is around 10(1) K. No significant magnetic moment is found on the Ni site as expected from previous susceptibility measurement. However, the Néel temperature is remarkably high considering only the Nd sublattice with its high Nd-Nd distances within the crystal structure. It is known that the magnetic interactions between rare-earth atoms of RKKY (Ruderman-Kittel-Kasuya-Yosida) type are indirect and mediated by the spin polarization of conduction electrons induced by the localized 4f-moments. This polarization which has an oscillatory character allows the interaction between localized 4f-moments and its absolute value decreases with increasing interatomic distance. The magnetic ordering temperature is also dependent on the density of states at the Fermi level. Among the other effects that can modulate this temperature one can cite the crystalline electric field ${ }^{41}$ and the hybridization between the $5 \mathrm{~d}$ orbitals of rare-earth and $3 \mathrm{~d}$ orbitals of transition metal ${ }^{42}$. In $\mathrm{NdNiMg}_{15}$, with a Néel temperature $\mathrm{T}_{\mathrm{N}}=9 \mathrm{~K}$, we observe very long $\mathrm{Nd}-\mathrm{Nd}$ distances, equal to $7.76 \AA$ and $7.19 \AA$ between $\mathrm{Nd}$ atoms inside and between the chains, respectively. In the literature, only few compounds having very long RE-RE distances (higher than $7 \AA$ to achieve a 3D network of RE-atoms) exhibit magnetic ordering temperature higher than $10 \mathrm{~K}$. In the series RERhIn5 (RE $=$ Rare-Earth) with tetragonal symmetry, $\mathrm{NdRhIn} 5^{43,44}$ is antiferromagnetic below $\mathrm{T}_{\mathrm{N}}=11 \mathrm{~K}$. The anisotropic structure is made of $\mathrm{NdIn}_{3}$ and $\mathrm{RhIn}_{2}$ layers with $\mathrm{Nd}-\mathrm{Nd}$ distances equal to 4.63 and $6.55 \AA$ in the $\mathrm{NdIn}_{3}$ layers and to $7.50 \AA$ between these layers. In the $\mathrm{RE}_{2} \mathrm{Pt}_{6} \mathrm{Ga}_{16}$ series, a magnetic transition $\mathrm{T}_{\mathrm{M}} \sim 13 \mathrm{~K}$ is observed for $\mathrm{RE}=\mathrm{Nd}^{45}$. These compounds crystallize with an hexagonal symmetry and are made of $\mathrm{Pt}_{2} \mathrm{Ga}_{14}$ double layers and RE-Ga disordered layers. The RE-RE distances are nearly equal to $4.3 \AA$ within the RE-Ga layers and to $8.7 \AA$ between them. The last example is $\mathrm{NdNiMg}_{5}{ }^{18}$ 
which exhibits antiferromagnetic ordering below $\mathrm{T}_{\mathrm{N}}=12 \mathrm{~K}$ and its structure is made of Nd-Ni graphite-type and Mg layers. The Nd-Nd distances are equal to 4.48 and $5.47 \AA$ inside the Nd-Ni layers and to 7.23 and $7.77 \AA$ between these layers. It can be noticed that in all the examples, a strong structural anisotropy is observed. To show that the $\mathrm{Nd}-\mathrm{Nd}$ distance is not the only criterion to take into account to estimate the magnetic transition temperature, the following examples are given. $\mathrm{Nd}_{2} \mathrm{Zn}_{17}{ }^{46}$ has Néel temperature close to $1.1 \mathrm{~K}$ whereas the Nd-Nd distances are ranging from 4.35 $\AA$ to 6.84 . Å. Moreover, in $\mathrm{NdNi}_{4} \mathrm{Mg}, \mathrm{Nd}$ atoms form a tridimensional FCC network with Nd-Nd distances of $5.02 \AA$, and no magnetic order is observed ${ }^{47}$. Band structure calculation are planned to better characterize the magnetic interactions in $\mathrm{NdNiMg}_{15}$ and to see if the Ni-atoms play a role in the interactions.

\section{Conclusion}

The search of new phases in the Mg-rich corner of the Nd-Ni-Mg was fruitful with the discovery of four phases; $\mathrm{NdNiMg}_{5}{ }^{18}, \mathrm{Nd}_{4} \mathrm{Ni}_{8} \mathrm{Mg}_{80}{ }^{20}, \mathrm{Nd}_{16} \mathrm{Ni}_{12} \mathrm{Mg}_{96}{ }^{21}$ and the title compound $\mathrm{NdNiMg}{ }_{15}$. Its structure is an ordered variant of the $\mathrm{V}_{15} \mathrm{Sb}_{18}$ structure where a 3-Dimensional network of $\mathrm{Mg}$-atoms and 1D-chains of alternating $\mathrm{Ni}$ and $\mathrm{Nd}$ atoms are coexisting. Such arrangement with a 3-Dimensional metallic network of $\mathrm{Mg}$ atoms and a covalent network of $\mathrm{Ni}$ and $\mathrm{Nd}$ atoms with lower dimensionality was previously observed in the other Mg-rich phases in the Nd-Ni-Mg system. Despite the very long Nd-Nd distances, higher than $7 \AA$, an antiferromagnetic ordering has been observed with $T_{N}=9 \mathrm{~K}$. The magnetic structure determined by neutron diffraction shows ferromagnetic coupling within the chains of $\mathrm{Nd}$ atoms which are running along the $c$-axis. The chains are ferromagnetically coupled within planes perpendicular to the [110] direction and these planes are antiferromagnetically coupled to neighboring planes forming a checkerboard-like magnetic structure. The metamagnetic transition observed on the $\mathrm{M}(\mathrm{H})$ curve can be interpreted as a spin-flip transition leading to an overall ferromagnetic structure. 


\section{References}

(1) Mordike, B.L.; Ebert, T., Magnesium - Properties - applications - potential, Mater. Sci. Eng. A 2001, $302,37-45$.

(2) Gray, J.E.; Luan, B. Protective coatings on magnesium and its alloys - a critical review. J. Alloys Compd. 2002, 336, 88-113.

(3) Staiger, M. P.; Pietak, A. M.; Huadmai, J.; Dias, G. Magnesium and its alloys as orthopedic biomaterials: A review. Biomaterials 2006, 27, 1728-1734.

(4) Kirkland, N.T.; Birbilis, N.; Staiger, M.P. Assessing the corrosion of biodegradable magnesium implants: A critical review of current methodologies and their limitations. Acta Biomater 2012, 8, 925-936.

5) Dornheim, M.; Doppiu, S.; Barkhordarian, G.; Boesenberg, U.; Klassen, T.; Gutfleisch, O.; Bormann R. Hydrogen storage in magnesium-based hydrides and hydride composites. Scr. Mater. 2007, 56, 841-846.

6), Jain, I. P.; Lal, C.; Jain, A. Hydrogen storage in Mg: A most promising material. Int. J. Hydrogen Energy 2010, 35, 5133-5144.

7) Uan, J.-Y.; Cho, C.-Y. ; Liu, K.-T. Generation of hydrogen from magnesium alloy scraps catalyzed by platinum-coated titanium net in $\mathrm{NaCl}$ aqueous solution. Int. J. Hydrogen Energy 2007, 32, 2337-2343.

8) Figen, A.K.; Coskuner, B.; Piskin, S. Hydrogen generation from waste $\mathrm{Mg}$ based material in various saline solutions $\left(\mathrm{NiCl}_{2}, \mathrm{CoCl}_{2}, \mathrm{CuCl}_{2}, \mathrm{FeCl}_{3}, \mathrm{MnCl}_{2}\right)$. Int. J. Hydrogen Energy, 2015, 40, 7483-7489.

(9) Abe, E.; Kawamura, Y. ; Hayashi, K. ; Inoue, A. Long-period ordered structure in a high-strength nanocrystalline Mg-1 at $\%$ Zn-2 at\% Y alloy studied by atomic-resolution Z-contrast STEM. Acta Mater. 2002, 50, 3845-3857.

(10) Kawamura, Y; Hayashi, K; Inoue, A; Masumoto, T. Rapidly Solidified Powder Metallurgy $\mathrm{Mg}_{97} \mathrm{Zn}_{1} \mathrm{Y}_{2}$ Alloys with Excellent Tensile Yield Strength above $600 \mathrm{MPa}$. Mater. Trans. 2001, 42, 11721176.

(11) Egusa, D.; Abe, E. The structure of long period stacking/order Mg-Zn-RE phases with extended nonstoichiometry ranges. Acta Mater. 2012, 60, 166-178.

(12) Kishida, K.; Nagai, K.; Matsumoto, A.; Yasuhara, A.; Inui, H. Crystal structures of highly-ordered long-period stacking-ordered phases with $18 \mathrm{R}, 14 \mathrm{H}$ and $10 \mathrm{H}$-type stacking sequences in the $\mathrm{Mg}-\mathrm{Zn}-\mathrm{Y}$ system, Acta Mater. 2015, 99, 228-239.

(13) Liang, G.; Huot, J.; Boily, S.; Van Neste, A.; Schulz, R. Catalytic effect of transition metals on hydrogen sorption in nanocrystalline ball milled $\mathrm{MgH}-\mathrm{Tm}(\mathrm{Tm}=\mathrm{Ti}, \mathrm{V}, \mathrm{Mn}, \mathrm{Fe}$ and $\mathrm{Ni})$ systems. $J$. Alloys Compd. 1999, 292, 247-252.

(14), Løken, S.; Solberg, J. K.; Maehlen, J. P.; Denys, R. V.; Lototsky, M. V.; Tarasov, B. P.; Yartys, V. A. Nanostructured Mg-Mm-Ni hydrogen storage alloy: Structure-properties relationship. J. Alloys Compd. 2007, 446-447, 114-120.

(15) Poletaev, A. A.; Denys, R. V.; Maehlen, J. P.; Solberg, J. K.; Tarasov, B. P.; Yartys, V. A. Nanostructured rapidly solidified $\mathrm{LaMg}_{11} \mathrm{Ni}$ alloy: Microstructure, crystal structure and hydrogenation properties. Int J. Hydrogen Energy, 2012, 37, 3548-3557.

(16) De Negri, S.; Giovannini, M.; Saccone, A. Phase relationships of the La-Ni-Mg system at $500{ }^{\circ} \mathrm{C}$ from 0 to 66.7 at.\% Ni. J. Alloys Compd. 2005, 397, 126-134.

(17) Huang, L. J.; Liang, G. Y.; Sun, Z. B. Hydrogen-storage properties of amorphous Mg-Ni-Nd alloys, J. Alloys Compd. 2006, 421, 279-282.

(18) Ourane, B.; Gaudin, E.; Zouari, R.; Couillaud, S.; Bobet J.-L. NdNiMg, a New Magnesium-Rich Phase with an Unusual Structural Type. Inorg. Chem. 2013, 52, 13289-13291.

(19) Ourane, B.; Gaudin, E.; Lu, Y. F. ; Zouari, R.; Ben Salah, A.; Bobet, J.-L. The new ternary intermetallic $\mathrm{NdNiMg}_{5}$ : Hydrogen sorption properties and more. Mater. Res. Bull., 2015, 61, 275-279.

(20) Luo, Q.; Gu, Q.-F.; Zhang, J.-Y.; Chen, S.-L.; Chou, K.-C.; Li, Q. Phase Equilibria, Crystal Structure and Hydriding/Dehydriding Mechanism of $\mathrm{Nd}_{4} \mathrm{Mg}_{80} \mathrm{Ni}_{8}$ Compound. Sci. Rep. 2015, 5, 15385. 
(21) Li, Q.; Luo Q.; Gu, Q.-F.; Insights into the composition exploration of novel hydrogen storage alloys: evaluation of the Mg-Ni-Nd-H phase diagram, J. Mater. Chem. A, 2017, 5, 3848-3864.

(22) Couillaud, S.; Gaudin, E.; Weill, F.; Gomez, S.; Stan, C.; Planté, D.; Miraglia, S.; Bobet, J. L. Structure of a new ternary compound with high magnesium content, so-called $\mathrm{Gd}_{13} \mathrm{Ni}_{9} \mathrm{Mg}_{78}$. Acta Mater. 2012, 60,4144 .

(23) Couillaud, S.; Gaudin, E.; Bobet, J.-L. Rich magnesium ternary compound so-called LaCuMg 8 derived from $\mathrm{La}_{2} \mathrm{Mg}_{17}$. Structure and hydrogenation behavior. Intermetallics 2011, 19, 336-341.

(24) Solokha, P.; De Negri, S.; Pavlyuk, V.; Saccone, A.; Fadda, G. Synthesis and Crystallochemical Characterisation of the Intermetallic Phases $\mathrm{La}\left(\mathrm{Ag}_{\mathrm{x}} \mathrm{Mg}_{1-\mathrm{x}}\right)_{12}(0.11 \leq \mathrm{x} \leq 0.21), \mathrm{LaAg}_{4+\mathrm{x}} \mathrm{Mg}_{2-\mathrm{x}}(-0.15 \leq \mathrm{x} \leq$ 1.05) and $\mathrm{LaAg}_{2+\mathrm{x}} \mathrm{Mg}_{2-\mathrm{x}}(0<\mathrm{x} \leq 0.45)$. Eur. J. Inorg. Chem. 2012, 4811-4821.

(25) Egami, M.; Abe, E. Structure of a novel Mg-rich complex compound in Mg-Co-Y ternary alloys. Scr. Mater. 2015, 98, 64-67.

(26) Linsinger S, Hoffmann RD, Eul M, Pöttgen R. Intermediate-valent Cerium in $\mathrm{Ce}_{2} \mathrm{Ru}_{4} \mathrm{Mg}_{17}$ and a Group-Subgroup Scheme for $\mathrm{La}_{9} \mathrm{Ru}_{4} \mathrm{In}_{5}$ and $\mathrm{Ce}_{9} \mathrm{Ru}_{4} \mathrm{Ga}_{5}$. Z. Naturforsch. 2012, 67b, 219-225.

(27) Hydrogen generation from Nd-Ni-Mg system by hydrolysis reaction, Alasmar, E.; Awad, A.S.; Hachem, D.; Tayeh, T.; Nakhl, M.; Zakhour, M.; Gaudin, E.; Bobet, J.-L. J. Alloys Compd. 2018, 740, 5260 .

(28) Bruker (2014) SADABS, version 2014/5, Bruker AXS Inc., Madison, Wisconsin, USA

(29) Petricek, V.; Dusek, M.; Palatinus, L. 2006, Jana2006, The Crystallographic Computing System, Institute of Physics, Praha, Czech Republic

(30) Palatinus, L.; Chapuis, G. SUPERFLIP - a computer program for the solution of crystal structures by charge flipping in arbitrary dimensions. J. Appl. Crystallogr. 2007,40, 786-790.

(31) Rodriguez-Carvajal, J. Recent advances in magnetic structure determination neutron powder diffraction. Physica B 1993, 192, 55-69.

(32) Pearson, W. B. The Crystal Chemistry and Physics of Metals and Alloys; Wiley: New York, 1972

(33) Emsley, J. The Elements, 3rd ed.; Clarendon Press: Oxford, UK., 1998.

(34) Swanson, H.E.; Tatge, E. Standard X-Ray Diffraction Patterns, J. Res. Natl. Bur. Stand. (U. S.) 1951, $46,318-327$

(35) Furuseth, S; Fjellvag, H. Synthesis and Crystal Structure of $\mathrm{V}_{15} \mathrm{Sb}_{18}$. Acta Chem. Scand. 1995, 49 , 417-422.

(36) Richter C. G.; Jeitschko, W. Preparation and Crystal Structure of the Titanium and Hafnium Bismuthides $\mathrm{Ti}_{8} \mathrm{Bi}_{9}$ and $\mathrm{Hf}_{8} \mathrm{Bi}_{9}$. J. Solid State Chem. 1997, 134, 26-30.

(37) Kleinke, H. Stabilization of the New Antimonide $\mathrm{Zr}_{2} \mathrm{~V}_{6} \mathrm{Sb}_{9}$ by $\mathrm{V}-\mathrm{V}$ and $\mathrm{Sb}-\mathrm{Sb}$ Bonding. Eur. J. Inorg. Chem. 1998, 9, 1369-1375.

(38) Assoud, A.; Kleinke, K. M.; Kleinke, H. The First Titanium Molybdenum Antimonide: $\mathrm{Ti}_{5.42} \mathrm{Mo}_{2.58} \mathrm{Sb}_{9}$, a Substitution variant of $\mathrm{Zr}_{2} \mathrm{~V}_{6} \mathrm{Sb}_{9}$. Z. Anorg. Allg. Chem., 2005, 631, 1924-1928.

(39) Lipatov, A.; Gribanov, A.; Grytsiv, A.; Rogl, P.; Murashova, E.; Seropegin, Y.; Giester, G.; Kalmykov, K. The ternary system cerium-palladium-silicon. J. Solid State Chem. 2009, 182, 2497-2509.

(40) Allman, R.; Hinek, R. The introduction of structure types into the Inorganic Crystal Structure Database ICSD, Acta Cryst. A 2007, 63, 412-417

(41) Noakes, D.R.; Shenoy, G.K. The Effect of a Crystalline Electric Field on the Magnetic Transition Temperature of Rare-Earth Rhodium Borides. Phys. Lett. 1982, 91, 35-36.

(42) Skorek, G.; Deniszczyk, J.; Szade, J.; Tyszka, B. Electronic Structure and Magnetism of Ferromagnetic GdTiSi and GdTiGe. J. Phys. Condens. Matter 2001, 13 (29), 6397-6409.

(43) Pagliuso, P.G.; Thompson, J.D.; Hundley, M.F.; Sarrao, J.L. Crystal-field-induced magnetic frustration in $\mathrm{NdMIn}_{5}$ and $\mathrm{Nd}_{2} \mathrm{MIn}_{8}(\mathrm{M}=\mathrm{Rh}$, Ir) antiferromagnets. Phys. Rev. B 2000, 62, 12266-12270. 
(44) Van Hieu, N. ; Shishido, H.; Takeuchi, T.; Thamizhavel, A.; Nakashima, H.; Sugiyama, K.; Settai, R.; Matsuda, T. D.; Haga, Y.; Hagiwara, M.; Kindo, K.; Onuki, Y. Unique Magnetic Properties of $\mathrm{NdRhIn}_{5}, \mathrm{TbRhIn}_{5}, \mathrm{DyRhIn}_{5}$, and HoRhIn 5. J. Phys. Soc. Jpn. $2006 ; 75 ; 074708$.

(45) Matsumoto, Y.; Ueda, T.; Ohara, S. Single crystal growth and heat capacity measurements of triangular lattice $\mathrm{R}_{2} \mathrm{Pt}_{6} \mathrm{Ga}_{15}(\mathrm{R}=$ rare earth). J. Phys.: Conf. Ser. 2016, 683, 012035.

(46) Marquina, C.; Kim-Ngan, N.H.; Bakker, K.; Radwanski, R.J.; Jacobs, T.H.; Buschow, K.H.J.; Franse, J.J.M.; Ibarra, M.R. Specific heats of $\mathrm{R}_{2} \mathrm{Zn}_{17}$ intermetallic compounds. J. Phys.: Condens. Matter 1993, 5, 2009-2016

(47) Shtender, V.V.; Denys, R.V.; Paul-Boncour, V.; Verbovytskyy, Yu.V.; Zavaliy, I. Yu. Effect of Co substitution on hydrogenation and magnetic properties of $\mathrm{NdMgNi}_{4}$ alloy. J. Alloys Compd. 2015, 639, 526532 
Table 1. Atomic positions and equivalent displacement parameters of $\mathrm{NdNiMg}_{15} . \mathrm{P4} / \mathrm{nmm}$ space group (origin choice 2) $a=10.0602(1)$ and $c=7.7612(2) \AA$.

\begin{tabular}{llllll} 
Position & Wyck. & $x$ & $y$ & $z$ & $\mathrm{U}_{\mathrm{eq}}\left(\AA^{2}\right)$ \\
\hline $\mathrm{Nd} 1$ & $2 \mathrm{c}$ & $1 / 4$ & $1 / 4$ & $0.93340(2)$ & $0.00968(4)$ \\
$\mathrm{Ni} 2$ & $2 \mathrm{c}$ & $1 / 4$ & $1 / 4$ & $0.43049(5)$ & $0.01473(8)$ \\
$\mathrm{Mg} 3$ & $4 \mathrm{~d}$ & 0 & 0 & 0 & $0.0166(2)$ \\
$\mathrm{Mg} 4$ & $8 \mathrm{i}$ & $3 / 4$ & $0.40182(5)$ & $0.15049(7)$ & $0.0155(1)$ \\
$\mathrm{Mg} 5$ & $2 \mathrm{~b}$ & $3 / 4$ & $1 / 4$ & $1 / 2$ & $0.0317(3)$ \\
$\mathrm{Mg} 6$ & $8 \mathrm{j}$ & $0.91021(4)$ & $0.91021(4)$ & $0.39055(7)$ & $0.0172(1)$ \\
$\mathrm{Mg} 7$ & $8 \mathrm{i}$ & $3 / 4$ & $0.98025(5)$ & $0.73297(7)$ & $0.0162(1)$ \\
\hline
\end{tabular}

Table 2. Interatomic distances in $\AA$ for $\mathrm{NdNiMg}_{15}$.

\begin{tabular}{|c|c|c|c|c|c|}
\hline \multirow[t]{7}{*}{ Nd1 } & $\operatorname{Mg} 6 \times 4$ & $3.3936(5)$ & $\operatorname{Mg} 5$ & $\operatorname{Mg} 4 \times 4$ & $3.1130(5)$ \\
\hline & $\operatorname{Mg} 7 \times 4$ & $3.4743(5)$ & & $\operatorname{Mg} 7 \times 4$ & $3.2610(5)$ \\
\hline & $\mathrm{Mg} 4 \times 4$ & $3.5627(5)$ & & & \\
\hline & $\mathrm{Mg} 3 \times 4$ & $3.5942(1)$ & $\operatorname{Mg} 6$ & $\mathrm{Ni} 2 \times 1$ & $2.6692(5)$ \\
\hline & $\mathrm{Ni} 2 \times 1$ & $3.8580(4)$ & & $\operatorname{Mg} 6 \times 1$ & $3.0682(6)$ \\
\hline & $\mathrm{Ni} 2 \times 1$ & $3.9032(5)$ & & $\mathrm{Mg} 4 \times 2$ & $3.1056(6)$ \\
\hline & & & & $\mathrm{Mg} 7 \times 2$ & $3.1870(7)$ \\
\hline \multirow[t]{5}{*}{$\mathrm{Ni} 2$} & $\mathrm{Mg} 7 \times 4$ & $2.6410(6)$ & & $\operatorname{Mg} 6 \times 2$ & $3.2235(6)$ \\
\hline & $\operatorname{Mg} 6 \times 4$ & $2.6692(5)$ & & $\operatorname{Mg} 3 \times 1$ & $3.2893(5)$ \\
\hline & $\mathrm{Nd} 1 \times 1$ & $3.8580(4)$ & & $\mathrm{Nd} 1 \times 1$ & $3.3936(5)$ \\
\hline & $\mathrm{Nd} 1 \times 1$ & $3.9032(5)$ & & & \\
\hline & & & $\mathrm{Mg} 7$ & $\mathrm{Ni} 2 \times 1$ & $2.6410(6)$ \\
\hline \multirow[t]{4}{*}{$\mathrm{Mg} 3$} & $\mathrm{Mg} 4 \times 4$ & $2.9437(3)$ & & $\operatorname{Mg} 6 \times 2$ & $3.1870(7)$ \\
\hline & $\mathrm{Mg} 7 \times 4$ & $3.2650(3)$ & & $\mathrm{Mg} 4 \times 2$ & $3.2427(5)$ \\
\hline & $\operatorname{Mg} 6 \times 2$ & $3.2893(5)$ & & $\operatorname{Mg} 5 \times 1$ & $3.2610(5)$ \\
\hline & & & & $\mathrm{Mg} 3 \times 2$ & $3.2650(3)$ \\
\hline \multirow[t]{7}{*}{ Mg4 } & $\mathrm{Mg} 3 \times 2$ & $2.9437(3)$ & & $\operatorname{Mg} 7 \times 2$ & $3.2758(5)$ \\
\hline & $\mathrm{Mg} 4 \times 1$ & $3.0547(8)$ & & $\mathrm{Mg} 4 \times 1$ & $3.4509(7)$ \\
\hline & $\operatorname{Mg} 6 \times 2$ & $3.1056(6)$ & & $\mathrm{Nd} 1 \times 1$ & $3.4743(5)$ \\
\hline & $\operatorname{Mg} 5 \times 1$ & $3.1130(5)$ & & & \\
\hline & $\mathrm{Mg} 4 \times 2$ & $3.1816(7)$ & & & \\
\hline & $\mathrm{Mg} 7 \times 2$ & $3.2427(5)$ & & & \\
\hline & $\operatorname{Mg} 7 \times 1$ & $3.4509(7)$ & & & \\
\hline
\end{tabular}




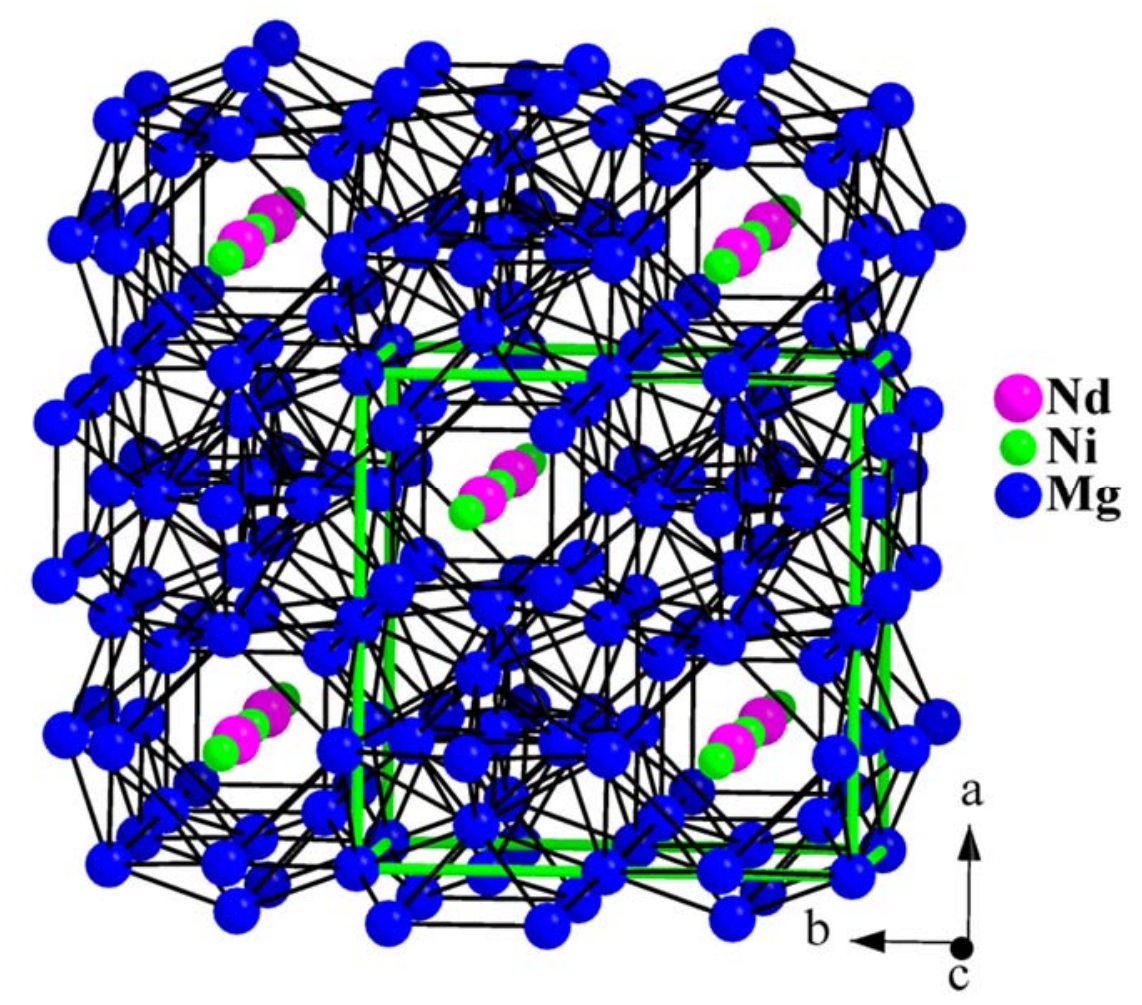

Figure 1. Perspective view of the structure of $\mathrm{NdNiMg}_{15}$. The $\mathrm{Mg}-\mathrm{Mg}$ bonds are drawn $(\mathrm{Mg}-$ Mg distance lower than $3.3 \AA$ ).

a)
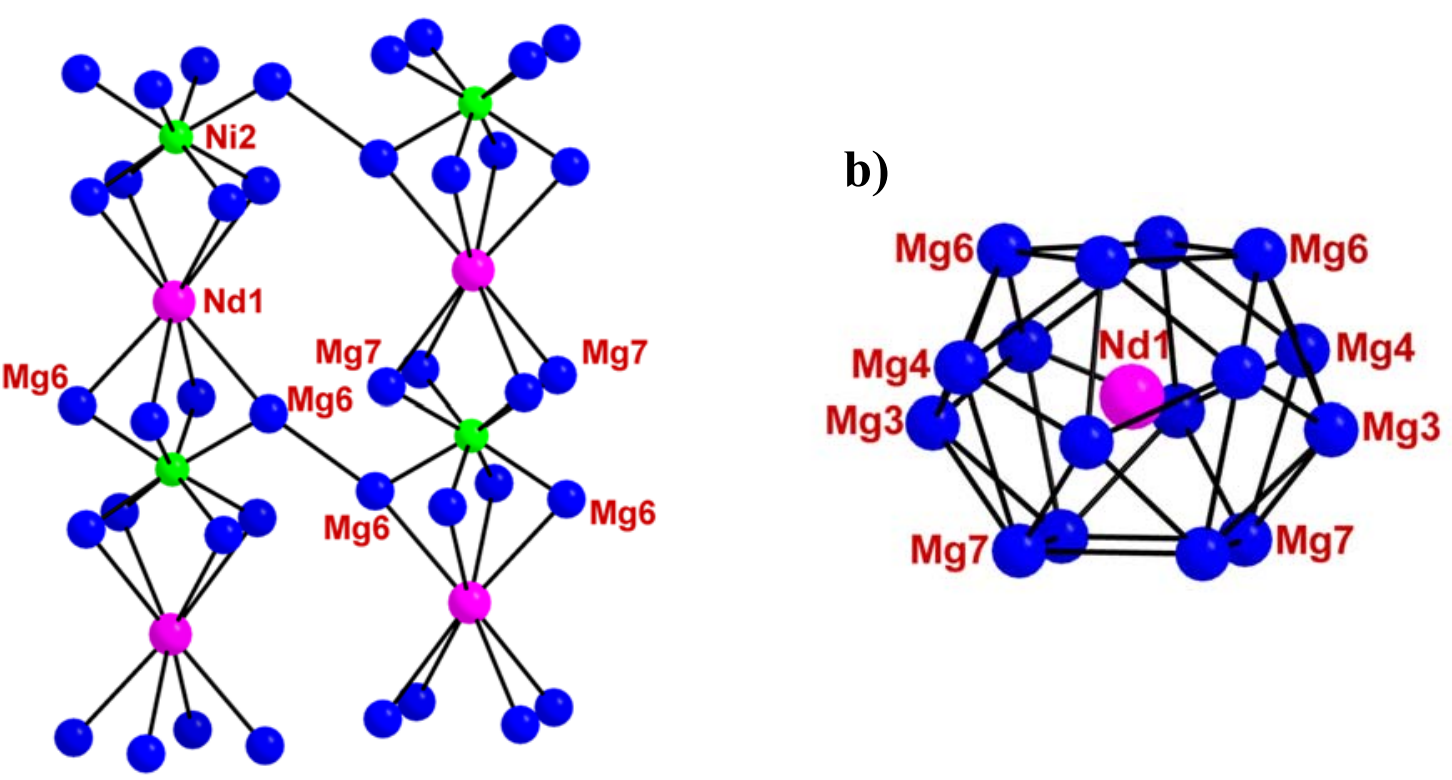

Figure 2. (a) $\mathrm{Nd}-\mathrm{Ni}$ chains of atoms with $\mathrm{Nd}-\mathrm{Mg}, \mathrm{Ni}-\mathrm{Mg}$ and $\mathrm{Mg} 6-\mathrm{Mg} 6$ bonds are drawn. (b) Environment of $\mathrm{Nd} 1$ position by considering distances $\mathrm{Nd}-\mathrm{Mg}$ lower than $3.6 \AA$. 
a)

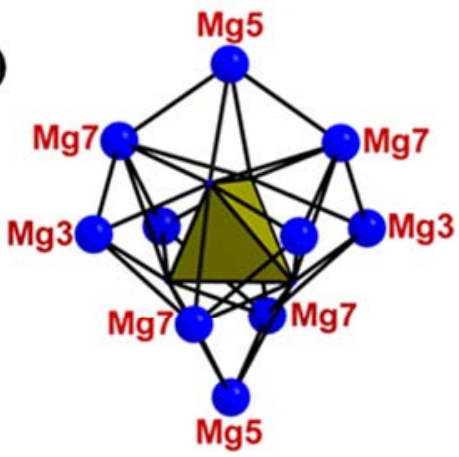

b)

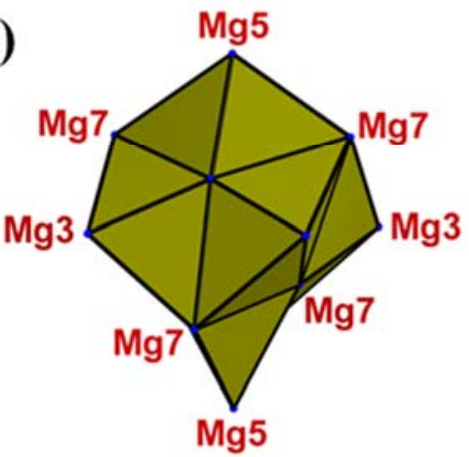

c)

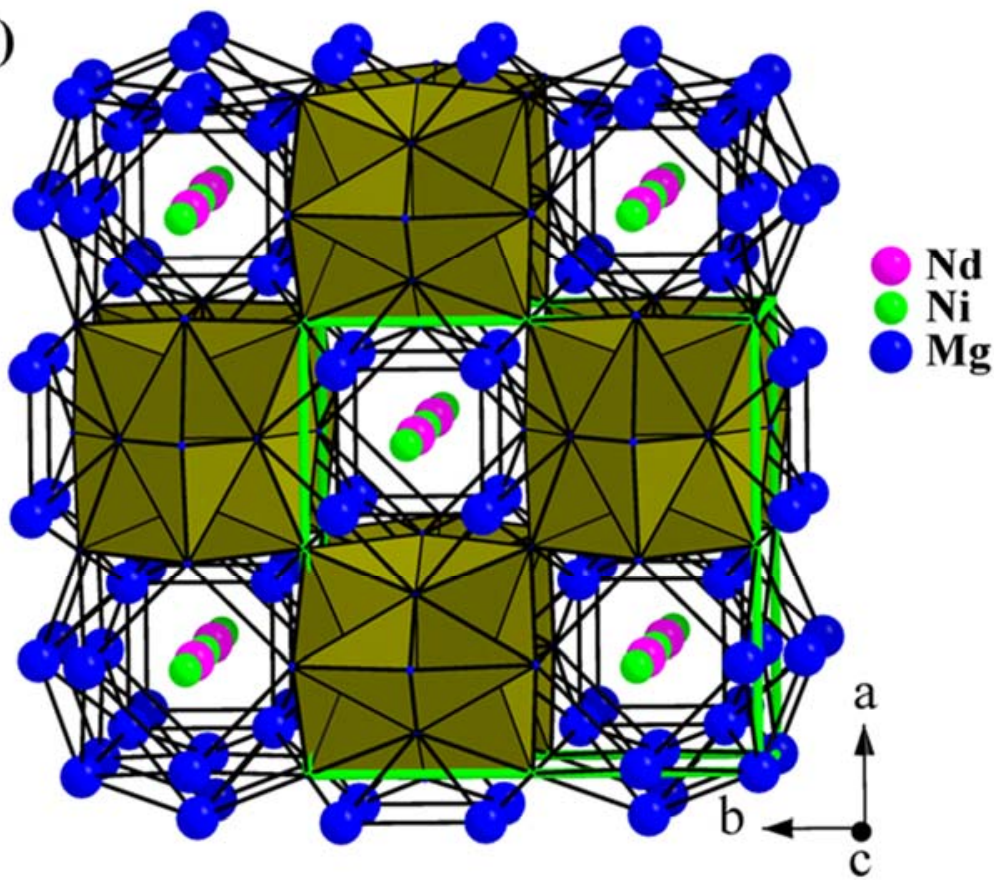

Figure 3. (a) Surrounding of a $[\mathrm{Mg} 4]_{4}$ tetrahedra drawn in green. (b) Same view as (a) with all $\left[\mathrm{Mg}_{4}\right]$ drawn in green. (c) View of the structure of $\mathrm{NdNiMg}_{15}$ with all $\mathrm{Mg}_{4}$ tetrahedra drawn in green.

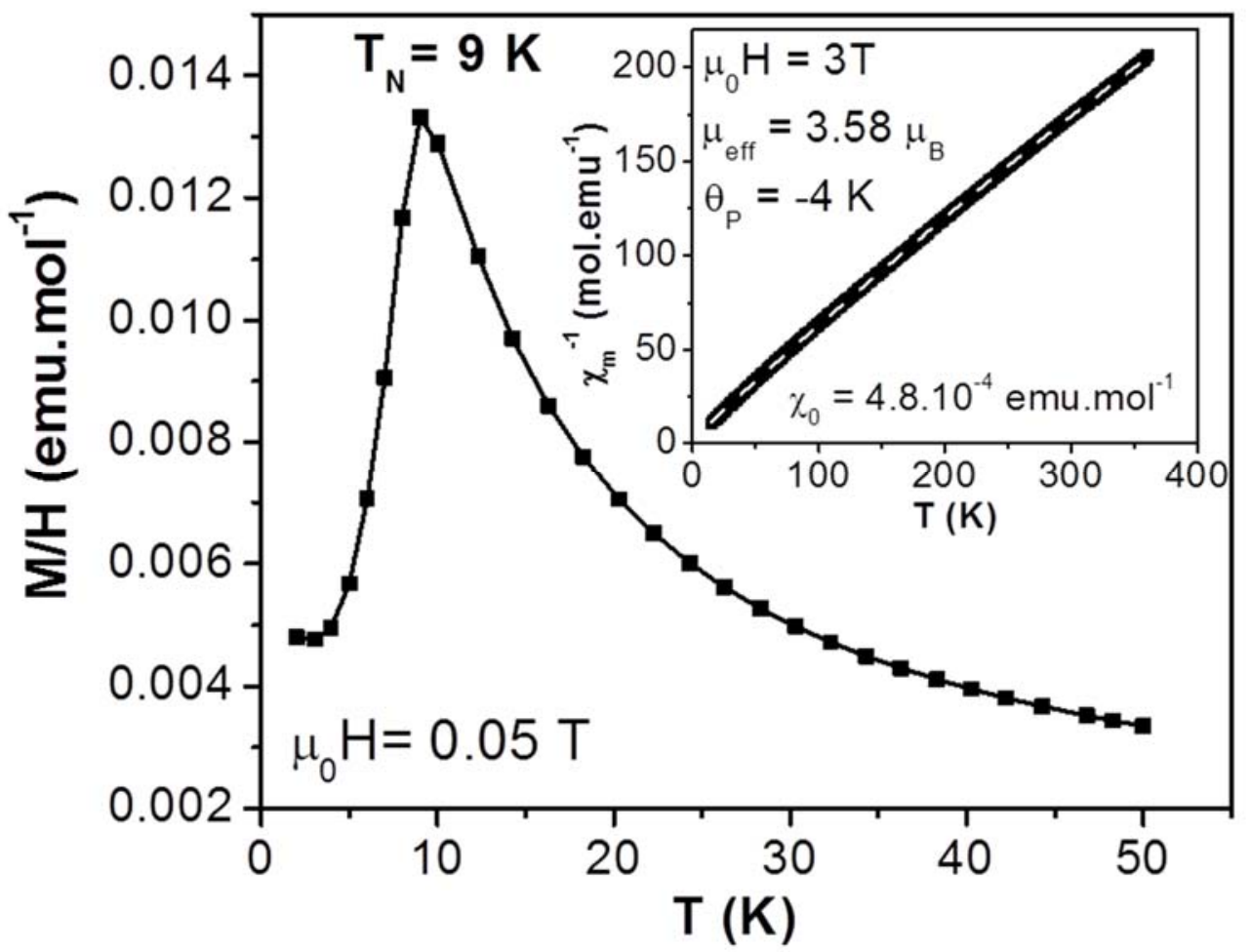

Figure 4. Temperature dependence of the magnetization divided by the magnetic field of $\mathrm{NdNiMg}$ 15. Inset: Inverse of the magnetic susceptibility versus temperature with the modified $\mathrm{Cu}-$ rie-Weiss fit represented in dashed line. 


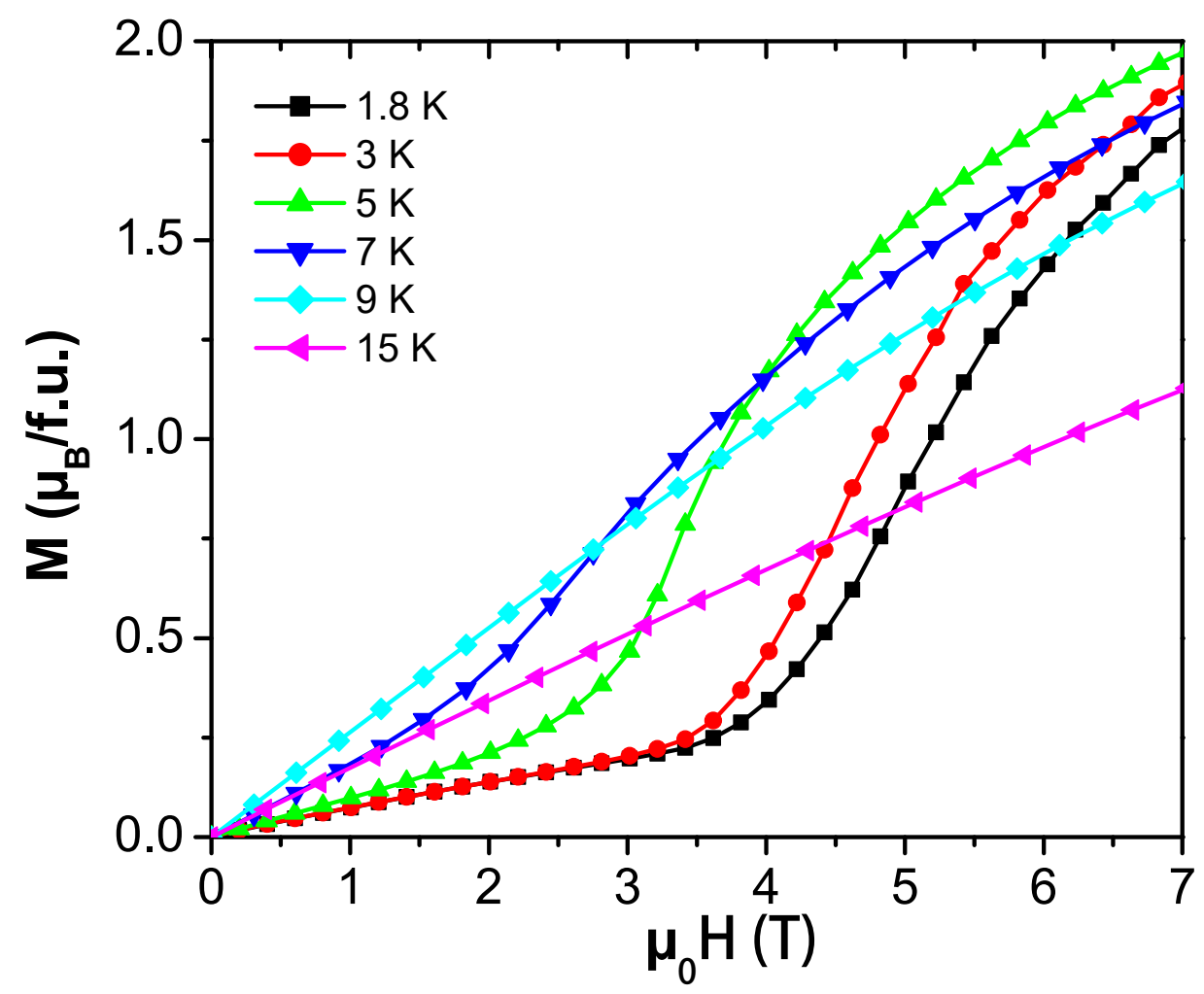

Figure 5. Field dependence of the magnetization curves at various temperatures between 1.8 and $15 \mathrm{~K}$.

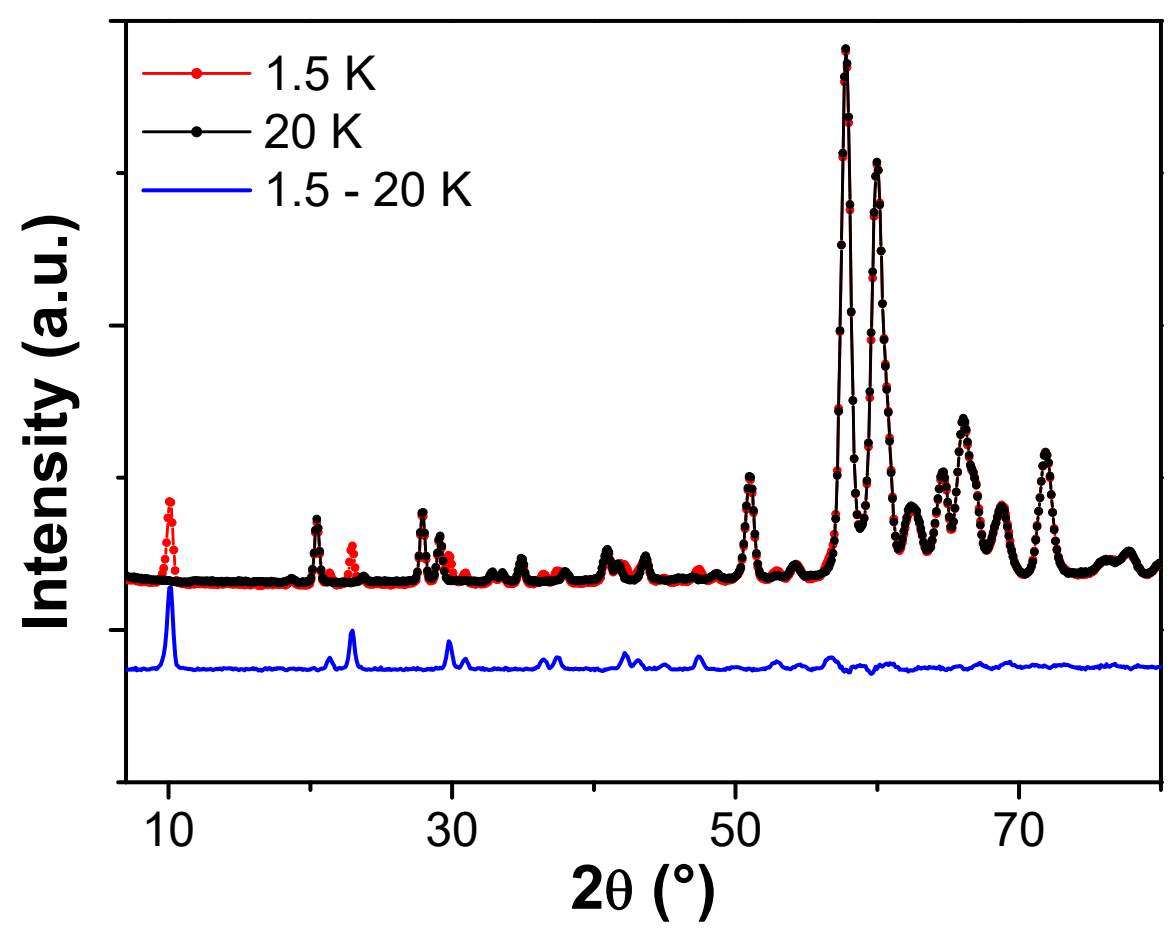

Figure 6. Neutron diffraction patterns of $\mathrm{NdNiMg}_{15}$ recorded at 1.5 and $20 \mathrm{~K}$ with the difference pattern between both temperatures showing the magnetic contribution. 


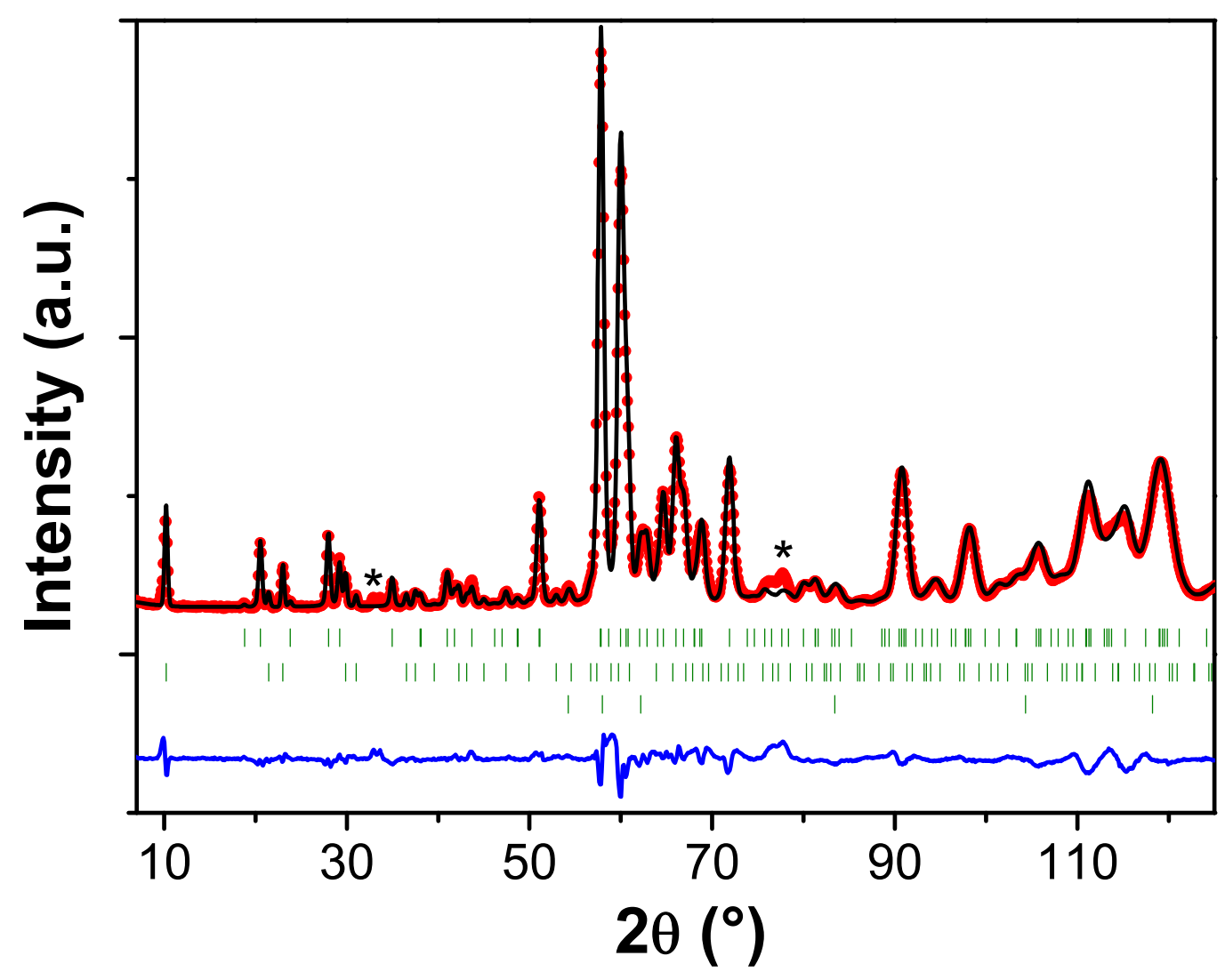

Figure 7. Rietveld refinement of the magnetic structure of $\mathrm{NdNiMg}_{15}$ from the neutron diffraction pattern at $1.5 \mathrm{~K}$. The two first lines of Bragg position ticks correspond to the nuclear and magnetic phases of $\mathrm{NdNiMg}_{15}$ respectively and the third one to residual $\mathrm{Mg}$ phase. The symbol * corresponds to the secondary phase $\mathrm{Mg}_{2} \mathrm{Ni}$.
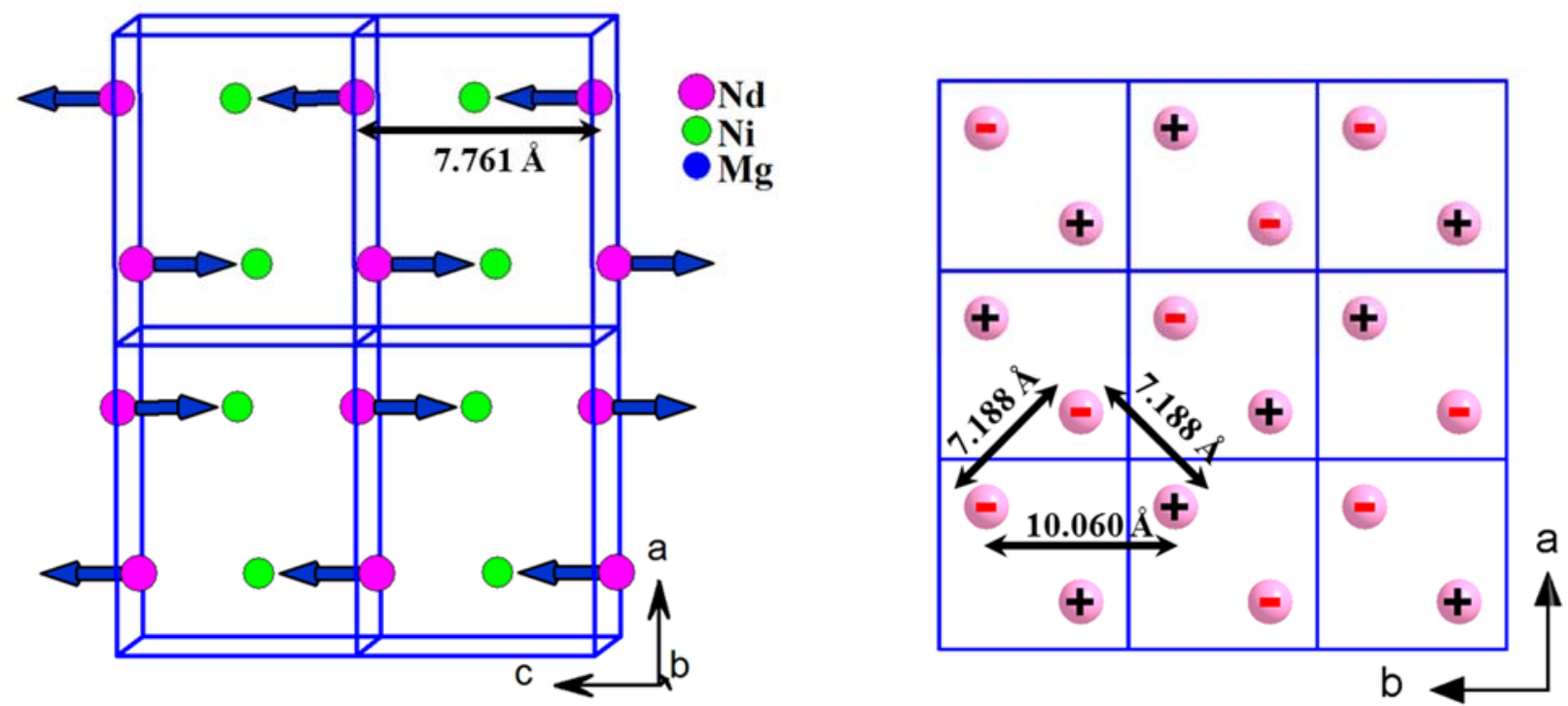

Figure 8. Magnetic structure of $\mathrm{NdNiMg}_{15}$. (left) Four unit cells are represented in blue and only $\mathrm{Nd}$ and $\mathrm{Ni}$ atoms are shown for clarity (right) Representation along the $c$-axis. The $\boldsymbol{+}$ and $\boldsymbol{-}$ signs represent the magnetic moments pointing forward and backward along the c-axis, respectively 


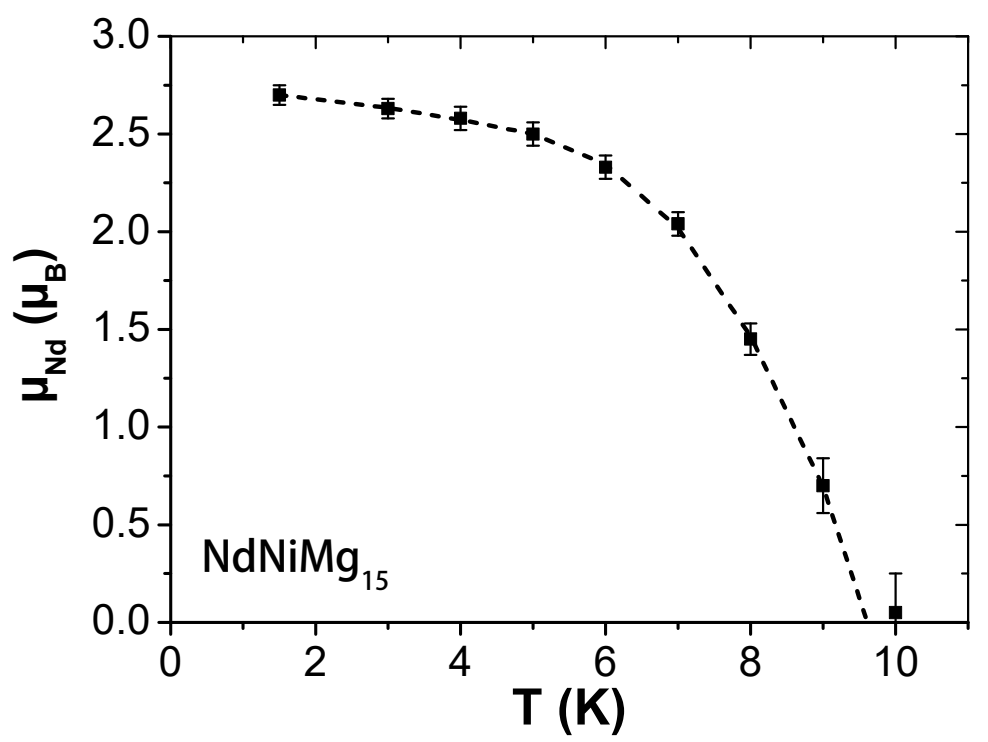

Figure 9. Temperature dependence of the magnetic moment of $\mathrm{Nd}$. The line is a guide for the eyes. 